\title{
DIVERSIDADE NA EDUCAÇÃO INFANTIL: CONSTRUINDO A IDENTIDADE E ROMPENDO O PRECONCEITO ATRAVÉS DA LUDICIDADE
}

\author{
Jozaene Maximiano Figueira Alves Faria ${ }^{7}$ \\ Rede Municipal de Uberlândia/MG \\ josy2209@yahoo.com.br \\ Fernanda Pereira da Silva Andrade ${ }^{8}$ \\ Rede Municipal de Uberlândia/MG \\ fpsandrade2907@hotmail.com
}

Título do Trabalho: Diversidade na educação infantil: construindo a identidade e rompendo o preconceito através da ludicidade

Autor(es): Jozaene Maximiano Figueira Alves Faria, Fernanda Pereira da Silva Andrade E-mail: josy2209@yahoo.com.br fpsandrade2907@hotmail.com

Resumo: Na Educação Infantil é fundamental incorporarmos ao cotidiano escolar atividades práticas que levam a diversidade cultural. É um trabalho contínuo e sistemático, que requer um olhar especial do educador no sentido de acompanhar os alunos em suas necessidades e capacidades, explorando as situações que surgem no contexto escolar de forma positiva. Trabalhar a diversidade por meio do jogo de faz-de-conta utilizando bonecos com diferentes características e a inversão de papéis sociais; (profissões, membros da família), abordando as diversidades culturais bem como suas particularidades, através do processo de conhecer, descobrir, interagir, crescer e apropriar-se de novos repertórios de forma prazerosa, rica e envolvente, com o objetivo de combater bullying, oportunizando vivências significativas, integrando as áreas do conhecimento, e realizar um trabalho sistemático de conscientização e combate ao preconceito. O presente relato de experiência tem como objetivo apresentar práticas pedagógicas que envolvem a construção de uma imagem positiva de si e dos outros, através de alguns projetos desenvolvidos na EMEI Zacarias Pereira da Silva, com crianças de 0 a 3 anos de idade, tendo como

\footnotetext{
${ }^{7}$ Especialista em Psicopedagogia Escolar, professora da Educação Infantil na rede Municipal de Ensino de Uberlândia

${ }^{8}$ Especialista em Tecnologia Digital aplicada à Educação; Especialista em Psicopedagogia e as Relações Psicoafetivas ; Graduação em Pedagogia; Especialista em Educação: Supervisora Escolar na Rede Municipal de Ensino de Uberlândia.
} 
metodologia: contação de histórias, pintura de telas, exploração de estampas de tecidos, jogos, brincadeiras, danças e contos de origem africana e afro-brasileira.

\section{Início da trajetória...}

Considerando a educação infantil como etapa primordial do desenvolvimento da criança, acreditamos que é nesse período que podemos contribuir para a formação de seres humanos mais éticos e capazes de conviver harmonicamente em sociedade.

o papel da educação infantil é significativo para o desenvolvimento humano, para a formação da personalidade e aprendizagem. Nos primeiros anos de vida, os espaços coletivos educacionais que a criança pequena frequenta são privilegiados para promover a eliminação de toda e qualquer forma de preconceito, discriminação e racismo. As crianças deverão ser estimuladas desde muito pequenas a se envolverem em atividades que conheçam, reconheçam e valorizem a importância dos diferentes grupos étnico-raciais na construção da história e da cultura brasileiras (BRASIL, 2009, p. 49).

Mesmo assim, em nosso cotidiano escolar, observamos algumas atitudes das crianças tais como: não querer brincar ou sentar-se ao lado determinados colegas, com isso acreditamos na importância criar de possibilidades de ensino-aprendizagem de conteúdos étnico-raciais, de maneirar lúdica.

As leis 10.639/2003 e 11.645/2008 tornam obrigatório, na educação básica, o ensino da História e Cultura Afro-Brasileira, Africana; e Indígena, respectivamente, alterando a LDB 9394/1996. Com isso buscamos meios para a implementação desses conteúdos na educação infantil, valorizando, a identidade e a cultura das famílias dos alunos e profissionais da escola promovendo momentos de reflexão, diálogo contribuindo para a formação integral de todos os envolvidos.

\footnotetext{
"A pluralidade cultural, isto é, a diversidade de etnias, crenças, costumes, valores etc. que caracterizam a população brasileira marca, também, as instituições de educação infantil. O trabalho com a diversidade e o convívio com a diferença possibilitam a ampliação de horizontes tanto para o professor quanto para a criança. Isto porque permite a conscientização de que a realidade de cada um é apenas parte de um universo maior que oferece múltiplas escolhas. Assumir um trabalho de acolhimento às diferentes expressões e manifestações das crianças e suas famílias significa valorizar e respeitar a diversidade, não implicando a adesão incondicional aos valores do outro." (BRASIL, 1998, p.77)
} 
Diante do exposto, no ano de 2014, a EMEI Zacarias Pereira da Silva incluiu em seu Projeto Político Pedagógico o projeto "Diversidade na Educação Infantil". Tendo como objetivos gerais:

Reconhecer e valorizar as manifestações culturais dos descendentes africanos e dos indígenas;

Construir uma imagem positiva de si mesmo e dos outros independentemente da etnia;

Observar a diversidade nos diferentes tipos de animais, pessoas, cores e frutas de maneira lúdica;

Estimular a convivência em grupo, respeitando a si e aos outros.

A partir desse projeto cada professor define seus objetivos específicos e metodologias para se trabalhar os conteúdos étnico-raciais com seus alunos.

\section{Um breve relato de experiência}

No ano de 2014, fui professora Regente II, ministrando os conteúdos de literatura e arte nas turmas de 0 a 3 anos intitulamos nosso projeto de "Somos diferentes?!". Tendo como objetivos específicos:

valorizar o ser humano, através da reflexão quanto às semelhanças e diferenças étnicas, sociais e relações familiares;

perceber-se e perceber o outro como diferente;

conscientizar a criança de que suas heranças, desde o cabelo até a cor da sua pele são oriundas de seus familiares.

Nossas ações foram norteadas por algumas obras literárias: "Menina bonita do laço de fita", de Ana Maria Machado; "A bonequinha preta", de Alaíde Lisboa de Oliveira; "Que cor é a minha cor", de Martha Rodrigues; "Minha família é colorida”, de Georgina Martins; "O livro da família", de Todd Parr.

A partir da contação de história desses livros, realizamos algumas atividades com alunos, dentre elas: construção de um painel coletivo e pintura sobre tela.

Levamos algumas imagens de revistas e conversamos sobre as diferenças entre as pessoas. Depois, contamos a história: "Menina bonita do laço de fita" 
utilizando bonecos dos personagens principais. Posteriormente construímos um painel coletivo com as imagens selecionadas pelas próprias crianças.
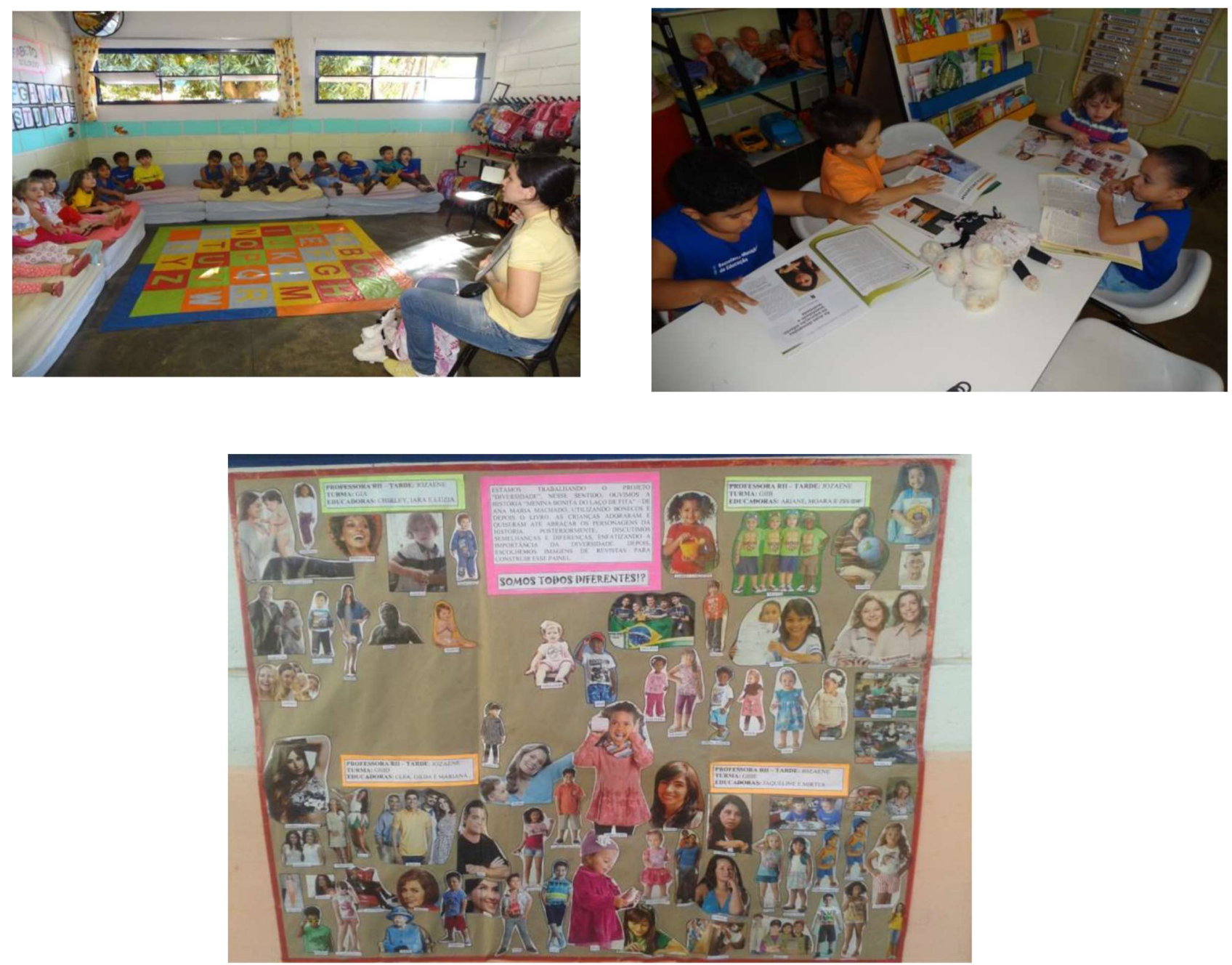
As turmas de 3 e 4 anos realizaram a pintura sobre tela inspirada em dois livros: "A bonequinha preta", de Alaíde Lisboa de Oliveira e "Que cor é a minha cor", de Martha Rodrigues. A partir do primeiro livro, fizemos uma janela no fundo da tela, uma cena da obra. A técnica utilizada foi xilogravura, que é um recurso de gravura em relevo, feita em madeira. Essa técnica foi adaptada para a educação infantil, usando isopor como um recurso artístico e didático que reconstrói o processo da xilogravura. Desenhamos a janela sobre $o$ isopor e as crianças passaram a tinta guache com rolinho. Posteriormente, cada aluno pintou a bonequinha preta com molde vazado, tinta e esponja. Para finalizar, com auxílio, as crianças colocaram os olhos, o cabelinho de lã e o vestido de tecido; também desenharam o nariz e a boca da bonequinha com cola colorida.
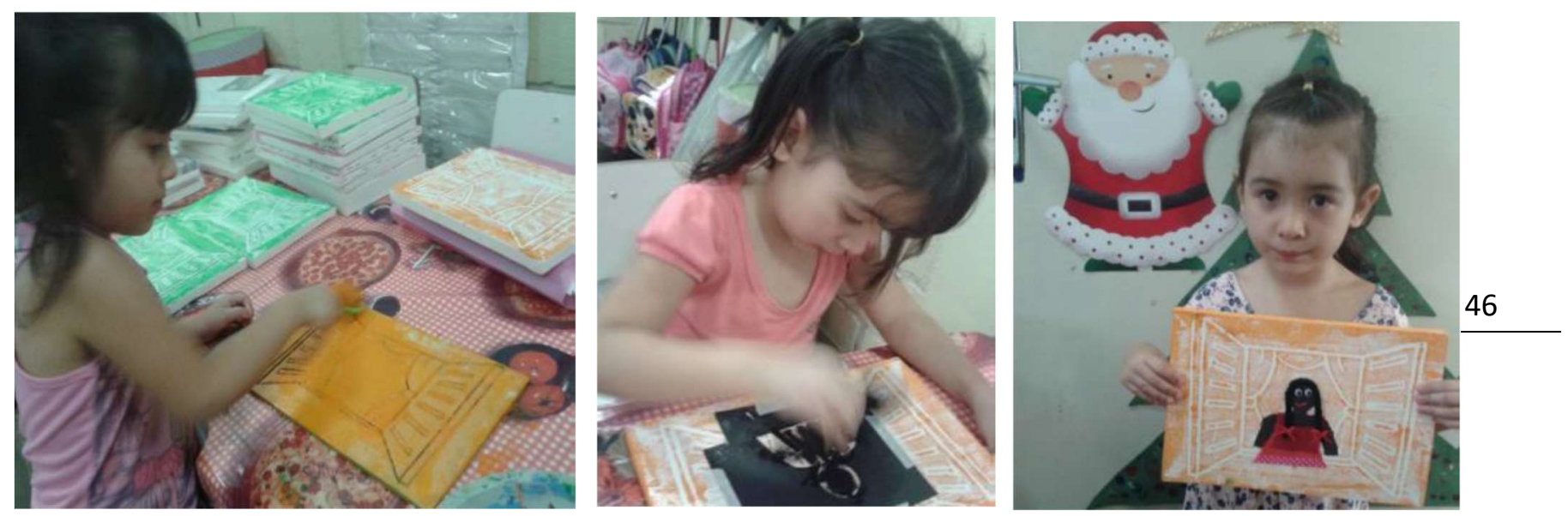

Com base no segundo livro, o fundo da tela foi pintado com esponja e tinta guache. Cada criança escolheu a cor da tinta com a qual mais se parecia com sua pele. Em seguida, foi feito o rosto com molde vazado. A professora colou os olhos com cola quente, posteriormente cada criança pintou o nariz e a boca utilizando o dedo indicador. Os alunos escolheram a cor do cabelo e pintaram de acordo com suas características (liso, encaracolado, curto, comprido) utilizando pincel. Colocaram a roupa em cada telinha utilizando tecido. Para finalizar, fizeram a tentativa de escrita do nome para identificar sua telinha. 

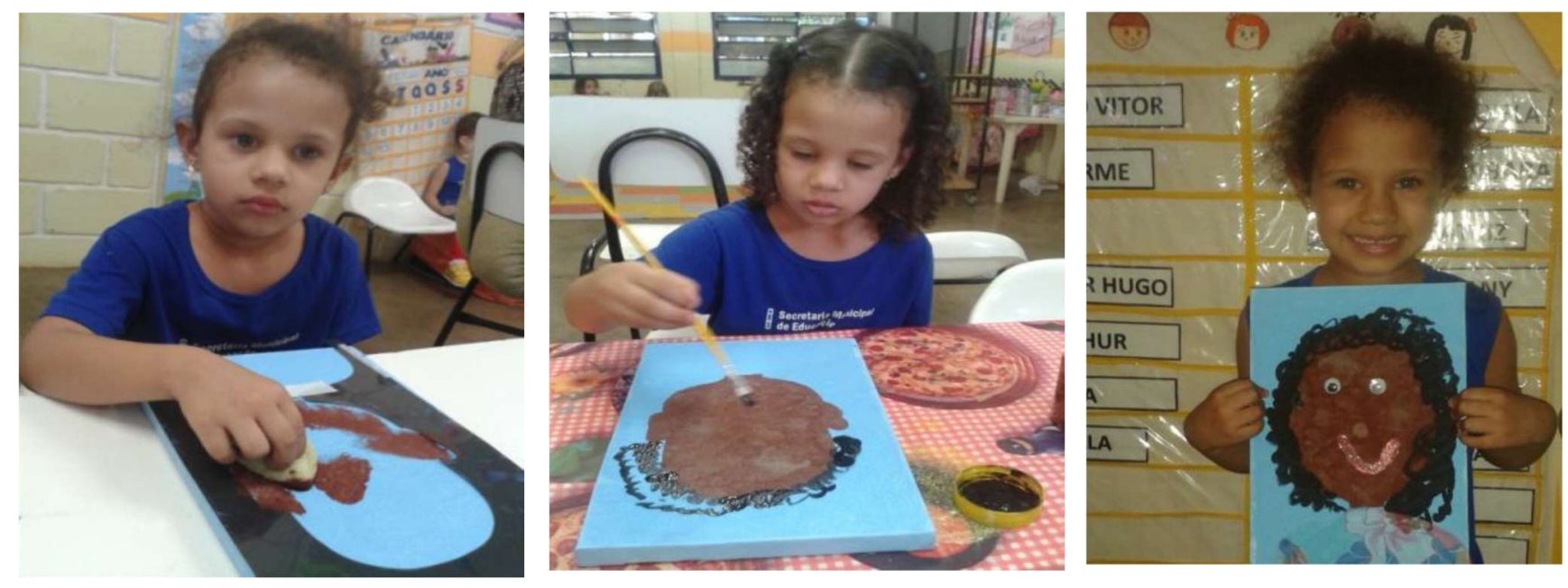

Como professora Regente I, em 2016, ano que o Brasil sediou as Olimpíadas, trabalhamos a heterogeneidade que permeia esse evento esportivo através do projeto "A diversidade nas Olimpíadas", envolvendo os eixos do conhecimento: Identidade, Natureza e Sociedade, Culturas, Artes Visuais. Os objetivos específicos foram:

$\square$ Conhecer as brincadeiras preferidas das crianças e de seus pais;

$\square$ Relacionar as brincadeiras com as principais modalidades esportivas das Olimpíadas;

$\square$ Valorizar a diversidade étnico-racial que permeia esse evento esportivo, com ênfase na cultura africana.

Para conhecer um pouco mais da africana fizemos um passeio à Casa da Cultura Graça do Aché para apreciar a exposição "Bamako/África”. Durante essa aulapasseio, assistimos vídeos com a rotina de algumas escolas da cidade de Bamako e um relato de experiência da professora mestre Beloní Cacique Braga, que esteve em uma missão humanitária nessa cidade trabalhando com a formação de professores. Nós achamos muito interessante e uma das coisas que mais chamaram a atenção foram os tecidos coloridos. 

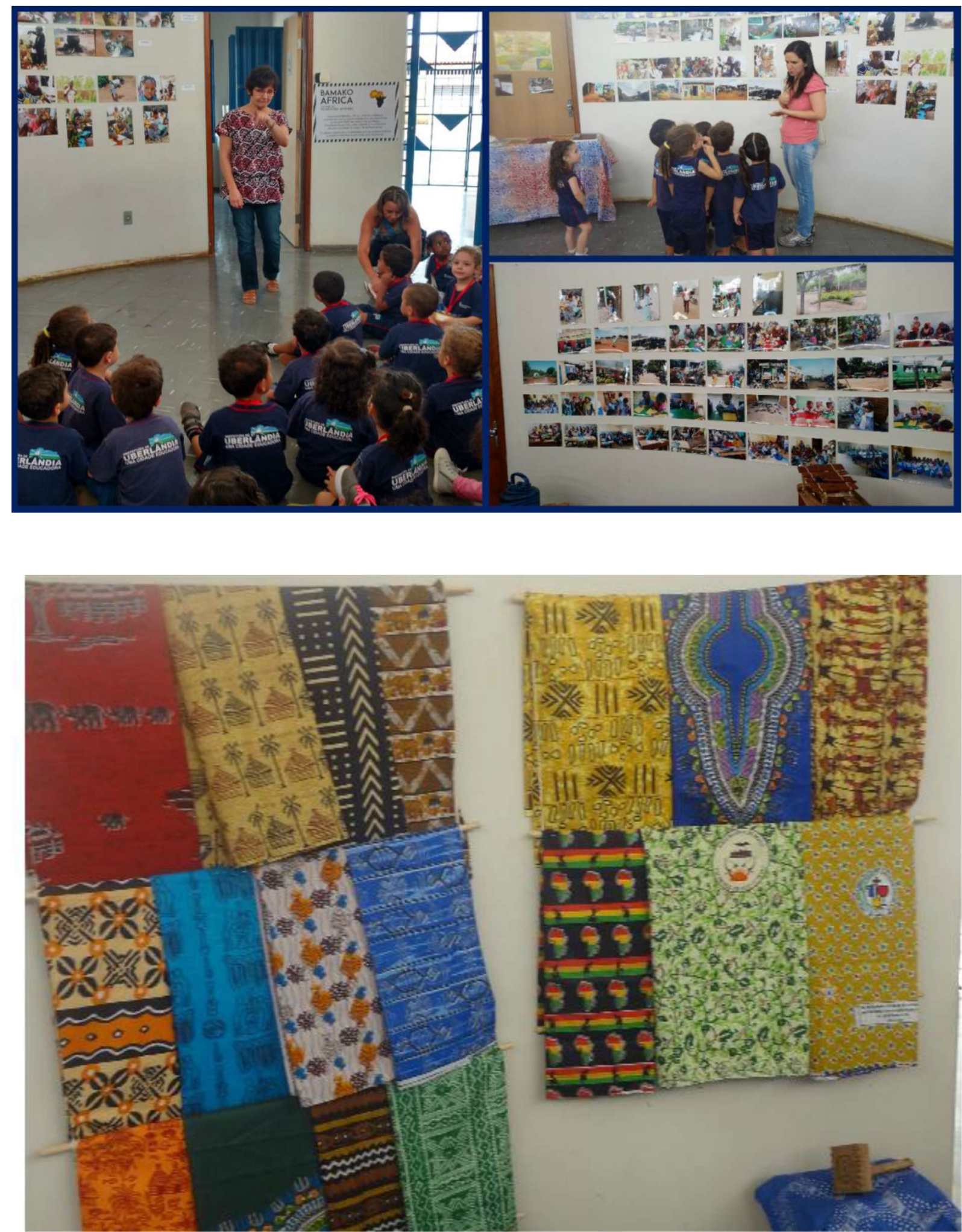
Para tornar esse momento ainda mais enriquecedor trouxemos algumas imagens de estampas de tecidos de origem africana para as crianças apreciarem, cada um escolheu a estampa que gostaria de pintar sua tela. Em parceria com a professora Regente II, realizamos a pintura em papel e posteriormente passamos para a tela.
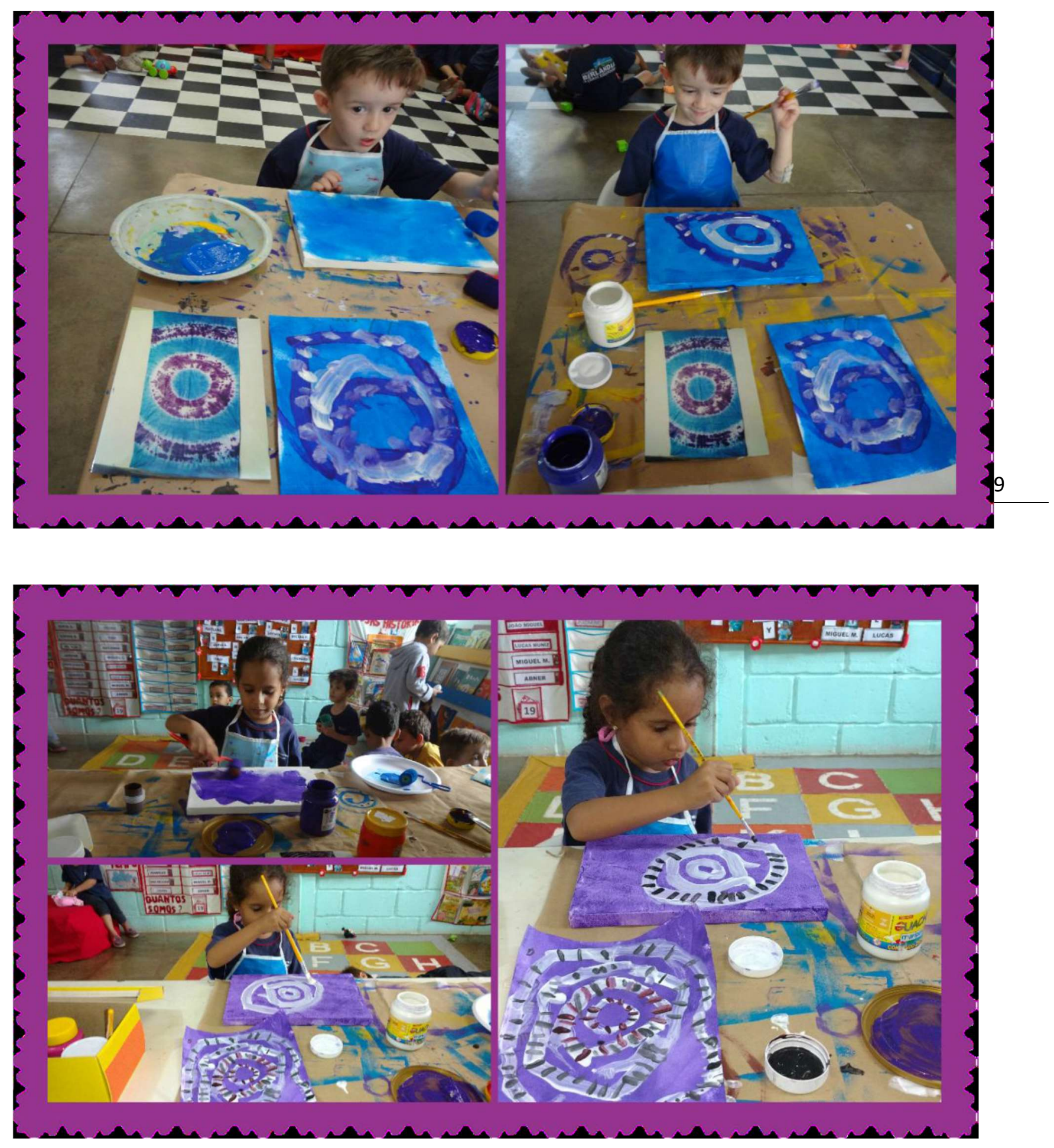


\section{Algumas considerações...}

Acreditamos que a caminhada é longa e estamos começando. Mas com a certeza de que contribuímos um pouquinho para que nossas crianças se tornem pessoas conscientes, responsáveis e que saibam conviver e respeitar a diversidade, em seu sentido mais amplo. Buscando sempre valorizar a cultura de cada aluno e da comunidade escolar.

\section{Referências bibliográficas}

BRASIL, MEC - SECRETARIA DE EDUCAÇÃO FUNDAMENTAL. Referenciais Curriculares Nacionais da Educação Infantil.Brasília: MEC/SEF/SEESP, 1998.

, Lei 10.639/2003, de 9 de janeiro de 2003. Altera a lei 9.394, de 20 de dezembro de 1996. Diário Oficial da União, Poder Executivo, Brasília.

,Diretrizes Curriculares Nacionais para a Educação das Relações ÉtnicoRaciais e para o Ensino de História e Cultura Afro-Brasileira e Africana. Brasília, DF, julho de 2004.

. Lei 11.645/08 de 10 de Março de 2008. Diário Oficial da União, Poder

Executivo, Brasília.

- Ministério da Educação. Plano Nacional das Diretrizes Curriculares Nacionais para a Educação das Relações Étnico-Raciais e para o Ensino de História e Cultura Afro-Brasileira e Africana. Brasília, DF: MEC/SECAD; SEPPIR, jun. 2009b.

. Ministério da Educação. Secretaria de Educação Continuada, Alfabetização, Diversidade e Inclusão. História e cultura africana e afro-brasileira na educação infantil / Ministério daEducação. Secretaria de Educação Continuada, Alfabetização, Diversidade e Inclusão. -Brasília : MEC/SECADI, UFSCar, 2014.

MACHADO. Ana Maria: Menina bonita do laço de fita. $7^{\circ}$ edição. São Paulo. Ártica, 2005.

MARTINS, Georgina. Minha familia é colorida. São Paulo: Edições S.M. 2005.

OLIVEIRA, Alaíde Lisboa de. A Bonequinha Preta. 23ed. Rio de Janeiro: Editora Lê,1998.

RODRIGUES, Martha. Que cor é a minha cor? Belo Horizonte: Mazza Edições, 2006

PARR, Todd. O livro da Família. São Paulo, Editora Panda, 2004. 